\title{
The Reification of Life
}

\author{
MICHAEL HAUSKELLER ${ }^{1}$
}

'What's wrong - fundamentally wrong - with the way animals are treated (...) isn't the pain, the suffering, isn't the deprivation. (...) The fundamental wrong is the system that allows us to view animals as our resources, here for us - to be eaten, or surgically manipulated, or exploited for sport or money. ${ }^{2}$

Tom Regan made this claim 20 years ago. What he maintains is basically that the fundamental wrong is not the suffering we inflict on animals but the way we look at them. What we do to them, what we believe we are allowed to do to them, is dependent on how we perceive or conceptualize them. We not only treat them as resources but prior to this we already think of them as resources, and when we look at them, all we tend to see is resources. In our perception of them they exist not for themselves but 'for us'. But obviously it can only be fundamentally wrong in a moral sense to view them that way if it is wrong in a factual sense, that is, if animals are in fact not 'for us'. But is it wrong?

\section{Animals as ends in themselves}

According to Immanuel Kant, our moral duties to our fellow human beings can all be traced back to the one rule never to treat each other (and oneself) merely as means but always at the same time as ends. The reason for this is that human beings, by virtue of their being capable of acting out of respect for the moral law and thus autonomously, have an intrinsic or absolute value that Kant calls dignity. That human beings have such an absolute value means, for Kant, that they (and in general all rational beings) by their very nature exist as ends in themselves. ${ }^{3}$ Thus the imperative always to treat them as ends and never merely as means is only an acknowledgement of their true nature. In contrast, all other beings have only a relative, extrinsic value and do not exist as ends in themselves. All value they can possibly have they do have by reason of their being valued by humans. It does not matter whether or not they are alive or conscious or sentient: they can never be ends in themselves unless they possess reason and are capable of acting out of respect for the moral law. Since animals lack this ability they are, again by their very nature, not ends in themselves, and we have no direct moral obligations towards them and are free to treat them, if it suits us, merely as means to our ends. Rational beings that exist as ends in themselves are called persons (the word 'person' being a nomen dignitatis), whereas all other beings, including all animals, are most appropriately called, and regarded as, things. ${ }^{4}$

The idea that animals might literally exist as means (thus justifying their being treated as means) is reminiscent of the Stoics' claim that the whole purpose of their existence is their usefulness to human beings. ${ }^{5}$ Kant, however, did not go quite that far. He merely made the negative claim that animals do not exist as ends, but not the positive claim that they actually do exist as means. The Stoics tended to think of animals as predisposed for human use, as natural born instruments, ${ }^{6}$ whereas Kant conceptualized them as 'things' because in his view they lack the necessary 
requirements for moral considerability. So in all practical, that is, moral respects, animals are just like any other non-rational thing. Their existence, their needs and desires, cannot be the basis for moral obligations. Morally speaking their lives and their well-being are a matter of indifference and there is no answer to the question how they ought to be treated. They do not have dignity (that is, an absolute value) but only a price, which means that they 'can be replaced by something else which is equivalent'. ${ }^{7}$ Thus, according to Kant, replaceability is the hallmark not only of inanimate things but of all living beings except humans.

However, replaceability is, contrary to what Kant suggests, not a property an object can possess as such, intrinsically, but only in relation to someone to whom it is replaceable and in relation to a certain aspect under which it is viewed. Anything can be replaceable for us if what matters to us is not the thing in its particularity, individuality, and uniqueness, but rather the thing as a representative of its kind. Because only then another thing of the same kind will do just as well. But what kind a thing is, again is not a question of its intrinsic properties but, instead, of our interest in it. To use a fairly trivial example, a coffee machine is not a coffee machine because it makes coffee (since it does many other things as well, and sometimes it does not make coffee). Rather, it is a coffee machine because it is designed to make coffee, we expect it to make coffee, and we primarily use it to make coffee. If it breaks we can either get it repaired or buy a new one, and it doesn't really matter which, because it is, to us, replaceable. We can replace it precisely because it does not matter to us which coffee machine we have as long as it does what it is supposed to do, that is, make coffee. Similarly, when it is suggested that animals are by their very nature replaceable they are already thought of as performing a certain function or having a certain use. We have an idea of what we want from them, how they should be like, what makes them good representatives of their kind. And this idea makes animals replaceable. That is why it is quite wrong to argue that we have no moral obligations to animals because they are, by their very nature, replaceable. Rather, we define them as replaceable because that provides us with a convenient justification not to pay any attention to what is good for them. Being a mere thing means being replaceable in the sense that there is no moral reason why we should not replace it. This is intuitively plausible with respect to inanimate objects like coffee machines. Although they are not in themselves replaceable there is also nothing about them that puts us under an obligation not to replace them. In that respect, however, animals are not mere things. They are different. They do have a good, and this good is their good and not anyone else's.

Judging by the way they behave, if animals could talk they would certainly disagree with both Kant and the Stoics. Their actions, and that is the only thing we can judge them by, are far from suggesting that they view themselves as replaceable, on the contrary. They are primarily oriented towards their own survival and to the attainment and defence of their own individual good. They clearly care for what happens to them. There is nothing in the way animals behave or in the way their bodies are shaped and organized that supports the idea that the purpose of their existence is anything but their own good. It certainly is not our good. And they would also regard themselves and their existence as ends in themselves. They may in fact be treated as means but they exist as ends in themselves. Regarding them merely as means, as things that can 
be used and replaced at will, is therefore not adequate to what they are. It is a practical denial of their independent existence and their biological integrity as a realization of their own good.

As the British philosopher William Wollaston has pointed out, a 'true proposition may be denied, or things may be denied to be what they are, by deeds, as well as by express words or another proposition. ${ }^{8}$ Since our actions are expressive of the beliefs we have we can declare that things are not as they are simply by acting in a certain way. If I, for instance, break a promise, I act as if such a promise has never been made and by acting that way (wrongly) declare that it has not been made. If I steal from somebody I treat someone else's property as my own and thereby declare that it is mine while in fact it is not. Wollaston believed that this fact explained the difference between good and evil or morally right and wrong actions. He gives the following illustration:

To talk to a post, or otherwise treat it as if it was a man, would surely be reckoned an absurdity, if not distraction. Why? because this is to treat it as being what it is not. And why should not the converse be reckond as bad; that is, to treat a man as a post; as if he had no sense, and felt no injuries, which he doth feel; as if to him pain and sorrow were not pain; happiness not happiness. This is what the cruel and unjust do.

However, it is not quite clear why it should be more morally wrong to treat a human being like a post than to treat a post like a human being, or more wrong to treat an animal as if it were a mere thing than to treat a mere thing as if it were an animal or a human person. Whereas the former seems to be morally wrong the latter just seems crazy. Somebody who is treating a post as if it were alive and sentient is out of their right mind, but their actions do not seem morally reprehensible. Wollaston realized that it would not be plausible to consider all actions that are expressive of a false proposition as equally morally wrong and tried to account for the different degrees of wrongness by distinguishing between actions with respect to the 'importance' of their consequences. Some actions are more wrong than others because certain things matter more than others. When, for instance, the happiness, welfare or life of a creature is at stake, denying their being what they are is more important than if their happiness, welfare and life were not affected. Now, it may seem that, by acknowledging that the degree in which an act is morally wrong depends on its consequences, Wollaston seriously undermines his claim that acts are morally wrong because they somehow deny the truth. However, Wollaston could defend his view by arguing that if an action causes suffering but does not deny the truth then it is not morally wrong despite the suffering it causes. For instance - as both Plato and Kant have argued - punishing someone for their crimes is not only justified (and perhaps advisable for the good of society) but also something that is literally owed to them. By being punished they are acknowledged as morally responsible beings, (in Kantian terms) as autonomous agents and thus as beings that possess intrinsic value and dignity. Did one refrain from punishing them one would in effect deny them their humanity, that is, deny them to be what they in fact are. Hence, since they are treated as morally responsible human beings no moral wrong is being committed even though suffering may be inflicted on them. It would appear then that even though a practical denial of the truth 
may not be sufficient to declare an act to be (seriously) morally wrong it may still be a necessary condition of moral wrongness.

\section{Reification}

Generally speaking, our practices influence and change the way we look at the objects involved in them. Conversely, the way we look at things determines the role we assign to them in our practices. Biotechnology is a human practice that has (and reflects) a tendency to transform living beings into scientific objects and into mere things. I call this process of transformation 'reification'. The term 'reification' is often used when abstract concepts are being treated as if they represented concrete things which can act and be acted upon. Reification in this sense is a fallacy, very similar in kind to the fallacy that Alfred North Whitehead called the 'fallacy of misplaced concreteness'. ${ }^{10}$ To give an example, 'pleasure' or 'happiness' tend to be reified in traditional utilitarian thinking when they are disconnected from the individual beings that are happy and feel pleasure and treated as if they had an existence of their own so that they can meaningfully be quantified, added and subtracted. The term 'life' is also a good candidate for this kind of reification. Life gets reified when, for instance, in the eyes of those who think of themselves as pro-life activists life acquires the status of an entity that has a value independent of those whose life it is. The status of being alive, which in fact qualifies a substance, is regarded and treated as if it were itself a substance: life as such.

However, this kind of reification is not what I wish to talk about here, at least not primarily. When I speak about the 'reification of life' I want the term 'reification' to be understood in the old Marxist sense of treating a subject as if it were a mere thing. The German word is 'Verdinglichung', which literally means 'turning [something that is not a thing] into a thing'. What the term addresses is the practical tendency to make a commodity (i.e., something that has a price but no intrinsic value) of an entity by disregarding every aspect of it other than those that can be utilized. Following the Kantian lead, this tendency is regarded particularly offensive when it is exhibited towards human beings, because humans should never be treated only as means but always as ends. But if animals, as I have pointed out above, are also ends in themselves in the sense that they aim at the fulfilment of their own being and do not primarily serve any other ends than their own by holding on to their lives and their particular kind of existence, ${ }^{11}$ then we may just as well adopt the Kantian imperative and conclude that animals, too, should never be treated merely as means but always at the same time as ends.

The concept of reification originates in Marx's critique of Capitalist society and was elaborated by Georg Lukacs. ${ }^{12}$ Only recently it was given a book-length treatment by Axel Honneth, ${ }^{13}$ who interpreted reification in a much wider context as an expression of 'Anerkennungsvergessenheit', which literally means forgetfulness of recognition. Honneth cites Adorno and Horkheimer who once remarked that all reification is a forgetting. What is forgotten is that the other is a subject just like oneself or, in more general terms, that the world outside does not exist exclusively for our convenience. This forgetting is expressed in a certain lack of emotional involvement or indifference - 'Teilnahmslosigkeit'. Reification is the effect of habitually adopting the perspective 
of a distant, neutral observer, a perspective that makes all objects appear as mere things. A certain primary relatedness to the world is lost.

The adoption of this neutral perspective is generally supposed to be a precondition of good science. Thus reification is required in order to conduct a scientific inquiry. In H.G. Wells's novel The Island of Dr Moreau we find this idea perfectly expressed by Dr Moreau himself when he remarks to his involuntary guest Prendick:

Pain! Pain and pleasure - they are for us, only so long as we wriggle in the dust (...) You see, I went on with this research just the way it led me. That is the only way I ever heard of research going. I asked a question, devised some method of getting an answer, and got - a fresh question. You cannot imagine what this means to an investigator, what an intellectual passion grows upon him. You cannot imagine the strange and colourless delight of these intellectual desires. The thing before you is no longer an animal, a fellow-creature, but a problem. ${ }^{14}$

This particular way of looking at animals is the result of what Michael Lynch called the 'transformation of the animal body into a scientific object' ${ }^{15}$ After having observed the behaviour and language of neuroscientists performing electron microscopic studies of regenerative processes in the brain of mammals, Lynch described the tension between mutually exclusive representations of laboratory rats, which on the one hand were initially perceived and throughout the experiments implicitly assumed to be naturalistic creatures, but were on the other hand spoken of and eventually treated as analytic products of research. The 'naturalistic animal' is the animal of our ordinary perception and interaction. Its presence is necessary but remains systematically unacknowledged in the research products. 'The 'analytic animal' therefore becomes the real animal in a scientific system of knowledge, while tacitly depending upon the naturalistic animal for its practical foundation. ${ }^{, 16}$ There is no indication in the way those experiments were conducted and the way the results were expressed that the entities being used were actually living beings. Every aspect that is supposedly irrelevant to the purpose of the experiment is systematically ignored. By gradually transforming the naturalistic animal - the living, conscious, and sentient creature - into an analytic entity and identifying the former with the latter, modern experimental science exemplifies forgetfulness. The knowledge is actually there but it is systematically suppressed and never openly acknowledged although implicit in the way researchers prepare the animals to yield the results they wish to attain: 'Animals are treated as holistic, living, reactive subjects to be soothed, cajoled, tricked, and gently led through procedures that transform them into analytic subjects. ${ }^{17}$ In the articles that were published after the experiments, animals were no longer present as living beings but as cases 'which demonstrated an abstract regenerative process in a generalized brain. 18

\section{Animal Models}

Various companies offer so-called research models for purchase. Sinclair, for instance, offer 'miniature swine as Models for Human Diabetes'. On their website, Sinclair first state what a serious problem the disease poses, and that for the lack of 
suitable large animal models, diabetes research has not sufficiently developed. Then, the product is presented:

\begin{abstract}
Miniature swine have many characteristics similar to humans that make them a suitable species to model human diseases. Miniature swine are omnivores, easy to handle, raise few ethical considerations, offer similar size to adult humans, have several organ systems very similar to humans in term of anatomy, physiology and metabolism, and test compounds can be administered through all routes of delivery, including trans-cutaneous delivery systems (patches). (...) Sinclair offers a new induced model of type 2 diabetes with dyslipidemia in miniature swine. The dyslipidemia observed is very similar to the one of diabetic humans and early atherosclerosis lesions have also been detected. The similarities of the lipid metabolism, vascular anatomy, capacity and collateral circulation of the coronary arteries between swine and humans make this animal model even more attractive. ${ }^{19}$
\end{abstract}

What is being offered here is not a conscious living being that cares for its own existence and strives to attain and preserve its own kind of good, but a model. A model is a kind of representation. It stands for something else. Normally it is a simplified version of a complex process or state which can be used to facilitate understanding of, or increase knowledge about, that process or state. If we want to know how something works or what effects certain actions have on it, and we cannot get hold of the real thing, or do not, for one reason or another, want to use it, a model is needed that is likely to provide the same information. A model may even be better suited for the purpose of gaining information because it can be constructed in such a way that many irrelevant aspects of what it is meant to represent are eliminated. However, an animal that is being used as a model for a human disease is not in itself a simplified version of that disease. It is, even when it is used a model, still a living being that cares for itself and has its own particular good. So instead of being eliminated, all those details that are deemed irrelevant for the purpose of gaining a certain kind of information are simply ignored - as much as this is possible. The properties that are explicitly acknowledged and highlighted are not properties of what Lynch called the naturalistic animal but either properties of the analytic animal or properties that facilitate their being turned into analytic animals. Being omnivores they can be fed almost anything, so feeding them will not be a problem. They are easy to handle, so no inconveniencies or surprises that might force their user to acknowledge their naturalistic side are to be expected. Their organ systems, metabolism and anatomy are similar to those of humans. The disease affects their bodies in the same way it affects the bodies of humans.

An animal model is perceived and used as a representation. Although a representation need have no similarity with what it represents (just as, conversely, a thing can be similar to another without representing it), ${ }^{20}$ in the case of animal models a certain similarity is necessary. The similarity is needed in order to achieve the research goal: it is the primary reason for using it as a model. On the other hand, the model also needs to be different, for if there weren't any difference between the representation and what it represents, one could just as well use the real thing. In this case the real thing would be a human being suffering from Diabetes. Yet experimenting on humans 
is thought to be unethical. In contrast, swine allegedly 'raise few ethical considerations', so the reason for not using human beings does not apply to animals. Ethical concerns appear to weigh less or not exist at all in the case of animals, and this justifies their being used as a model. In fact, however, it is the way they are represented that allows us to lower their moral status to a negligible degree.

In every act of representation there is an object (that which is represented) and a mode of representation (that as which the object is represented). Every representation involves a certain characterization of an object. In the case of animal models, the animal represents a human as the bearer of a certain disease. It is meant to exemplify this human disease. Being meant to exemplify, the animal model is, qua model, a reduction. Similarity is important only in a certain respect, whereas in other respects the dissimilarity is equally important, namely dissimilarity in respect to everything that might be considered ethically relevant, such as life, sentience, conscience, an inner perspective, a subjective existence. These properties are not positively absent in animal models but they are systematically overlooked. Hence the dissimilarity is not intrinsic to the object but a mental, linguistic and social construction. It is a result of what Honneth calls forgetfulness (of a prior recognition). Everything that is not relevant to the purpose (and that may possibly create a meaningful relationship between the animal and its user) is pushed into the background, is suppressed. The animal is regarded and, more importantly, subsequently treated as a mere model or, in more general terms, a tool. Its intrinsic value is concealed and its instrumental value emphasized. At the same time the instrumentalization is being hidden. The fact that the animal only becomes a model by virtue of the way humans relate to it (conceptualize and treat it) is forgotten, and what is essentially the result of an interest-guided contraction of one's visual and mental focus is transformed into an ontological fact. Awareness that one is using an animal as a model is lost and replaced by the belief that one is actually using an animal model.

The process of reification passes through several stages. The starting point is an individual living, conscious, and sentient animal. This is initially recognized but eventually forgotten (Honneth's Anerkennungsvergessenheit). A selective use of language is then employed to deflect attention from those properties that tend to be regarded as giving rise to intrinsic value and thus moral status, and simultaneously to confine attention to properties that are most likely to be instrumentally valued. The next and most important step is the transformation of an instrumental perspective into an ontological fact: the animal now appears to not only be used as a model but to be a model, thereby retroactively justifying its being used as a model. As a result, the animal appears to be an indefinitely usable thing that is completely at our disposal.

Incidentally, this crucial transformation of an instrumental perspective into an ontological fact can be seen as an instance of reification in the first sense of the word, which I mentioned briefly at the beginning of this paper. It is an instance of treating an abstract concept as if it represented a concrete thing. Not only the animal is reified (by being conceptualized and treated as a mere thing) but also the term 'model' is being reified by using it as if it represented the whole reality of the object it refers to instead of a certain use this object can be subjected to. 
Language helps to sustain this crucial deception. The way we speak about a thing not only reflects but also shapes our perception of it and facilitates the process of reification. Just as it is important in warfare to verbally dehumanize the enemy and all potential victims of one's own aggression in order to dissolve possible moral scruples and instinctive inhibitions towards killing fellow human beings, ${ }^{21}$ animals are being transformed verbally in order to deflect attention from the fact that they are individual living creatures that care for their lives and have a good of their own just as we do. What needs to be forgotten is that animals are not made for our convenience, do not exist as means to our ends, but are ends in themselves. Only natural beings can be ends in themselves. Pure (non-living) artefacts, on the other hand, are never ends in themselves because they are made for a certain purpose. By employing a certain terminology natural beings are for all practical purposes turned into artefacts. 'To speak of organisms as machines legitimizes our treatment of them as artefacts, as completely knowable and transparent objects and of their lives as having no ethical significance. ${ }^{22}$

\section{Super-reification through genetic modification}

A further step in the reification of living creatures is reached when animals are genetically manipulated in such a way that those features that, for some reason or other, hamper our use of them are eliminated and other features that are conducive to their intended use are accentuated or added. Quite rightly Lynch remarked that 'the genetic design and domestication of laboratory animals anticipates their use as analytic subjects. ${ }^{23}$ Animals are not only spoken of as tools and treated as tools, they are quite literally being created as tools. Instead of putting up with the naturalistic animal and trying to ignore it as best as we can, gene technology allows us (or promises to allow us) to create animals that are less and less naturalistic and more and more analytical - increasingly perfect research tools. Mice, for instance, have been used for almost a century to model human diseases because they are cheap, easy to hold, and, most importantly, develop conditions similar to those of humans such as cardiovascular disease, cancer, or diabetes. However, by specific gene targeting (homologous recombination in embryonic stem cells) genes can now be inserted, deleted, modified or substituted so that other human diseases can be modelled that do not normally strike mice, such as cystic fibrosis or Alzheimer's. Knockout mice, knockin mice, and transgenic mice can be specifically designed according to the needs of the customer. They are custom-made by various companies that offer their services to the requiring researcher: Tell us what you want and we will get it for you. The U.S. National Institutes of Health (NIH) advertise Knockout mice as a resource that 'will serve to further the value of the mouse as a powerful and important tool in the study of human health and disease. ${ }^{24}$ Ozgene, a company specializing on the fabrication and marketing of genetically modified mice and rats, advertise their products as 'the most sophisticated and valuable tools in functional genomics and drug target validation. ${ }^{25}$

The instrumental value of the mouse as a research tool is thus not only emphasized but it is effectively raised. Although its intrinsic value is thereby not diminished but in fact remains the same it gets even harder to recognize this and not to forget it. Genetically modified mice are still living, 'naturalistic' creatures but they have also 
become artefacts into whose very being a purpose has been introduced that is not their own. This external purpose is the sole reason for their existence. It is not that, like animals raised for food, they owe their existence to the fact that we have discovered how to use them for our purposes but rather that they owe their very nature to what we are planning to do with them. Their utility is the reason not only for the fact that they are but also for what they are. They already enter the world as human inventions and consequently are increasingly regarded as the intellectual property of their inventors, as products for which it is thought proper to claim and award a patent.

The first patent on an animal was issued in 1988 for a mouse genetically engineered to susceptibility for breast cancer, the so called Harvard oncomouse. Since then more than 500 patents on animals have been issued, including cats, dogs and primates. The patent was awarded despite the fact that the U.S. law prohibited that naturally occurring organisms be patented. But of course it was argued that the oncomouse was not a naturally occurring organism. It was not a product of nature but a human product. Although genetically modified animals may not be entirely artificial they are no longer entirely natural either: they are something like living artefacts or, to use the very fitting term that was introduced into the debate by Nicole Karafyllis, 'biofacts'.

But doesn't the successful creation of such biofacts mean that we have finally managed to bring animals into existence that actually do exist as means (to our ends)? We could then concede that Kant was wrong to claim that only human beings exist as ends in themselves and accept that most animals do too, and may still want to hold that animals that are specifically designed for a certain purpose do clearly not exist as ends in themselves but truly as means. They are not only used as instruments, they are instruments. And if they do exist as means, if they are instruments, then it seems it can hardly be inadequate to treat them as such. We would, after all, only use them the way they are meant to be used and treat them exactly as what they are. Our actions would be truthful, would be adequate to their nature and therefore morally justified.

However, even a biofact is still a living creature that pursues its own ends despite the fact that it has been created to serve our ends. It is not in itself meant to be used in any way, ie, it does not exist as a tool, and its being designed as a tool does not provide sufficient moral justification for its exploitation. The fact that our children owe their existence to us does not give us the right to treat them as our property. And if we had conceived them for a certain purpose (eg, to take over the family business or to donate bone marrow to a sibling suffering from leukemia), we would still be morally obligated to let them live their own lives and pursue their own ends, which might turn out to be very different from what we intended them to be. Even if we had used gene technology to render them more suitable for our purposes, that would not entitle us to treat them as our property. The same holds for animals. We may design them at our convenience but that does not give us the right to treat them any way we please. It would if animals were things, but living beings cannot be turned into things. The process of reification is never complete and remains largely conceptual and perceptual. Biotechnology just gives us the means to consolidate our blindness towards the independent reality of an animal's existence. 


\section{Instrumentalisation and Integrity}

Alan Holland once remarked that if it could only be shown that the genetic modification of animals is incompatible with showing respect to them then this would be the best case against it. ${ }^{27}$ Now, as we have seen, the genetic modification of animals is an attempt to turn a living organism into an instrument that is perfectly adapted to its intended use. The process of reification that has started as a specific way of looking at, thinking and talking about, and treating a living organism, is pushed to its limits by actually re-modeling the organism so that its instrumental value is raised. Thus the animal's instrumental value becomes so prominent for our perception of it that its intrinsic value is effectively buried underneath it. Does this constitute a violation of the animal's integrity?

Biological integrity consists in the ability to live according to one's own natural ends or teloi. Instrumentalization, or what I have called reification, is a process or an act that aims at either ignoring or eliminating these ends and replacing them with artificial, human-made ends. If those human-made ends are achieved at the expense of the animal's natural ends then clearly its biological integrity is impaired. However, it is at least theoretically possible (although not very likely) that an animal is viewed and used as a tool without this having any effect on its ability to live according to its own natural ends. In other words, it could be nothing but a tool for us and not be any worse for it. Would its use then still be a violation of its integrity and, therefore, morally wrong? Or is reification morally wrong only because of what we are likely to $d o$ to the animal as a result, but not wrong in itself, as a specific human attitude towards animals, a certain way of thinking about and looking at them?

It is difficult to separate an attitude from its practical application and expression. And indeed, if the conceptual and perceptual transformation of a living animal into a resource, an instrument, or a mere thing, had no effect whatsoever on the way we treat animals, Tom Regan would hardly have regarded it as the 'fundamental wrong'. So perhaps we should concede that the instrumental attitude towards animals is not in itself a violation of their integrity. However, it seems that the respect we owe them (due to their being living creatures with a good of their own and their leading lives that we can recognize as intrinsically valuable) covers more than just our actions. It does not only demand that we not restrict their ability to pursue their natural ends but also that we acknowledge their true nature (according to which they are not things) in our thinking.

The Kantian imperative that we never treat each other merely as a means but always at the same time as an end does not primarily command a certain kind of behaviour towards others but first of all a certain kind of mental attitude. In our daily lives we often treat others as means to our ends. For instance when we go to a shop and buy a newspaper the shopkeeper is being used by us as a means to acquire what we want There is nothing wrong with that, as long as we don't forget that the shopkeeper is also a human being who does not exist for our convenience and who deserves our respect. This respect is something we expect from others even where it doesn't make much difference to what actually happens. The shopkeeper would be deeply offended 
if he learned that we regarded him as a mere instrument without any intrinsic value whatsoever. And he would be offended even if we treated him no differently. The point is that we do not want to be 'used' even when we are used, that is, we expect others not to think of us merely as a means but always also as an end. If we find out that we have in fact been treated merely as a means we are not only disappointed but morally outraged. We feel that it is morally wrong to 'use' someone like this, to relate to people as if they were tools. We are not primarily concerned about the possible or actual effects of being used but about the fact itself. Neither do we think that the wrong consists in our feeling used. Rather, we object very strongly to our being used. Even if we never learned about it we would still not want it to happen. Even if nothing in the actual course of events had been different it would still make a difference to us. We feel that by being regarded merely as an instrument our individual reality is being denied. We are living, conscious beings that exist for their own sake and not for anyone else's, and we want this fact to be acknowledged and our identity as notthings to be respected. Yet animals, too, are living, conscious beings that exist for their own sake, and although they cannot demand respect for it they do deserve it just as much as humans do.

${ }^{1}$ Department of Sociology and Philosophy, University of Exeter, UK m.hauskeller@exeter.ac.uk

${ }^{2}$ T. Regan. 1985. The Case for Animal Rights. In In Defense of Animals. Peter Singer, ed. New York: 13-26.

${ }^{3}$ I. Kant. 1883. Fundamental Principles of the Metaphysic of Morals. Kant's Critique of Practical Reason and Other Works on the Theory of Ethics, translated by Kingsmill Abbott. London: 46.

${ }^{4}$ Ibid.

${ }^{5}$ Cicero, De Natura Deorum: II.37. Although humans have a purpose, too, they do not serve any other creature's (nor the Gods') interests. Humans are meant to contemplate and imitate the universe and thereby to actualize their rational nature (ibid.). All other living beings exist in order to aid this purpose. Even though reason permeates everything, including animals, it is only in humans that reason exists in a pure form. Therefore animals are not of "primary importance" (Epictetus. 1916. The Discourses and Manual. Together with fragments from his writings. Translated with Introduction and Notes by P.E. Matheson. 2 vols. Oxford: II.8). For a more detailed discussion of the Stoics' view on animals cf. M. Hauskeller. 2007. Biotechnology and the Integrity of Life. Aldershot. Ashgate: ch. 8.

${ }^{6}$ This does not mean that they are meant to be used for a particular purpose only. Although horses are said to be for riding, cattle for ploughing, etc., it is their general purpose that is morally relevant, and that is to serve human needs and wants. In the Stoics' view there is no reason (for instance, no Aristotelian intrinsic telos and according natural good) why we should not find new uses for animals as long as it benefits us and thus reason itself. On the contrary, reason demands to use them any way they can be used. Again, for more detail cf. Hauskeller. 2007. ch. 8.

${ }^{7}$ Ibid, p. 53

${ }^{8}$ W. Wollaston. The Religion of Nature Delineated, $8^{\text {th }}$ ed. 1750. London: 6 .

${ }^{9}$ Ibid, p. 20

${ }^{10}$ A. N. Whitehead. 1926. Science in the Modern World. Cambridge. Whitehead defines this fallacy (p. 72 ) as the 'error of mistaking the abstract for the concrete'.

${ }^{11}$ It might be objected that this is not Kant's sense of 'ends in themselves' since Kant explicitly rests his claim that humans are ends in themselves, ie, have intrinsic value, or dignity, on their alleged (potential) moral autonomy, which animals lack. But autonomy was not part of Kant's concept of dignity. Rather, autonomy was thought to be the only possible (or legitimate) source or ground for dignity. That the necessary requisite for being an end in oneself is moral autonomy was Kant's personal conviction. However, the close link that Kant intended to establish between moral autonomy and intrinsic value is far from compelling and it is by no means clear why there should not be other grounds for intrinsic value beside moral autonomy, for instance the existence of a good of one's own. 
${ }^{12}$ G. Lukacs. 1971. History and Class Consciousness. Cambridge, Mass.

${ }^{13}$ A. Honneth. 2005. Verdinglichung. Frankfurt/M.

${ }^{14}$ H.G. Wells. 1921. The Island of Dr. Moreau. London: 93.

${ }^{15}$ M. Lynch. Sacrifice and the Transformation of the Animal Body into a Scientific Object: Laboratory Culture and Ritual Practice in the Neurosciences. Social Studies of Science 1988; 18 (2): 265-289.

${ }^{16} \mathrm{Ibid}, \mathrm{p} .267$

${ }^{17}$ Ibid, p.281

${ }^{18}$ Ibid. p.266

${ }^{19} \mathrm{http}: / /$ www.sinclairresearch.com/diabetes.htm

${ }^{20}$ For the concept of representation cf. N. Goodman. 1976. Languages of Art. Indianapolis.

${ }^{21}$ Cf. M. Hauskeller. 2001. Versuch ueber die Grundlagen der Moral. Munich: 165-189.

${ }^{22} \mathrm{~T}$. Warkentin. 2006. Dis/integrating animals: ethical dimensions of the genetic engineering of animals for human consumption. AI \& Society 2006; 20: 82-102, p.100.

${ }^{23}$ Lynch, op. cit. note 12, p.274.

${ }^{24} \mathrm{http} / / / \mathrm{www}$. nih.gov/science/models/mouse/deltagenlexicon/theresource.html

${ }^{25} \mathrm{http://www.ozgene.com}$

${ }^{26}$ N. Karafyllis. 2001. Biologisch, natuerlich, nachhaltig. Philosophische Aspekte des Naturzugangs im 21. Jahrhundert. Tuebingen and Basel.

${ }^{27}$ A. Holland. 1990. The Biotic Community: a philosophical critique of genetic engineering, p.170. In The Bio-Revolution. Cornucopia or Pandora's Box. Peter Wheale and Ruth McNally, eds. London: 166-174. 